Editorial

\title{
Introduction to Communicating on/with Minorities
}

\author{
Leen d'Haenens * and Willem Joris \\ Institute for Media Studies, KU Leuven, 3000 Leuven, Belgium; E-Mails: leen.dhaenens@kuleuven.be (L.d'D.), \\ willem.joris@kuleuven.be (W.J.) \\ * Corresponding author
}

Submitted: 21 January 2019 | Published: 5 February 2019

\begin{abstract}
This editorial delivers an introduction to the Media and Communication thematic issue on "Communicating on/with Minorities" around the world. This thematic issue presents a multidisciplinary look at the field of communicating on and with different members of minority groups who, based on gender, ethnicity, sexual orientation, or a background in migration, experience relative disadvantage and marginalization compared to the dominant social group. The contributors to this thematic issue present a variety of professional contexts (i.e., portrayals in journalistic content, in fiction and non-fiction audiovisual content, on social media platforms and in health care). Taken together, the contributions examine various theoretical angles, thereby adopting new research directions through the use of quantitative, qualitative or mixed methodologies.
\end{abstract}

\section{Keywords}

communication; ethnic minorities; gender; immigrants; intersectionality; media; refugees; sexualities

Issue

This editorial is part of the issue "Communicating on/with Minorities", by Leen d'Haenens and Willem Joris (KU Leuven, Belgium).

(C) 2019 by the authors; licensee Cogitatio (Lisbon, Portugal). This article is licensed under a Creative Commons Attribution 4.0 International License (CC BY).

\section{Introduction}

This thematic issue of Media and Communication aims at further enriching the debate on how to communicate on and with minority groups around the world. The latter are seen in a particular professional context (e.g., media production or health communication). They can be part of media content, produce or access it on a variety of platforms. Media representations on variegated media outlets, both mainstream or niche media, and reactions with regard to these representations among majority and minority audiences are dealt with in this thematic issue. This includes posing questions such as: Whose viewpoints are looked at and whose are being ignored? What media and communication infrastructures are in place to adequately cater for minority groups? What practices of media access, uses and representations exist, what structural inequalities occur, and how can these be remedied? Banking on the above, the ten contributions in this the- matic issue of Media and Communication critically address the field from various disciplinary, theoretical and empirical dimensions. Several contributions study intersectionality given their focus on individuals who simultaneously hold membership in multiple minority groups.

\section{Contributions in This Thematic Issue}

Hanne Vandenberghe (2019) opens this thematic issue with "Representation of Women in the News: Balancing between Career and Family Life". The article starts out with an automated content analysis of the occurrence of women in the coverage of two Dutch-speaking Belgian newspapers so as to investigate whether the representation of women has changed between 2005 and 2015. Vandenberghe combines this longitudinal automated analysis with an in-depth qualitative analysis of the portrayal of two women stepping into a leadership position. 
Koen Panis, Steve Paulussen and Alexander Dhoest (2019) investigate the representation of ethnic minorities in non-fiction programmes on the Flemish public service broadcaster. In their article "Managing SuperDiversity on Television", they adopt a multi-method approach, combining qualitative content analysis of clips and episodes of non-fiction programmes with focus group interviews with participants from different ethnocultural minority background.

In their contribution "ICT Use and Digital Inclusion among Roma/Gitano Adolescents", Maialen Garmendia and Inaki Karrera (2019) analyze the way in which the digital divide affects the Roma or Gitano minors in Spain. Through interviews with adolescents and social workers, the authors focus their analysis of inequality on three main areas: i.e., media provision, participation and protection.

Darien Perez Ryan and Patrick E. Jamieson (2019) present a pilot study named "Risk and Culture of Health Portrayal in a U.S. Cross-Cultural TV Adaptation". The authors assess the health-related content of a Spanishlanguage telenovela and its English adaptation to test whether the English-language version 'Americanizes' the content by increasing risky and reducing healthy portrayals on screen.

David De Coninck, Koen Matthijs, Marlies Debrael, Rozane De Cock and Leen d'Haenens (2019) offer a four-country comparison (i.e., Belgium, France, the Netherlands and Sweden) when looking into the public sentiment towards migrants and refugees. In "Unpacking Attitudes on Immigrants and Refugees" they analyze, among other things, to which extent household composition, news media consumption and trust in media are related to attitudes towards immigrants and refugees. The authors administered an online survey of the adult population in the four countries $(N=6,000)$.

Miguel Angel Casado, Carmelo Garitaonandia, Gorka Moreno, and Estefania Jimenez (2019) describe the Internet use by immigrant children in Spain, taking into account both the risks and opportunities. Based on indepth interviews with children from the Maghreb region, Ecuador and Sub-Saharan Africa, combined with interviews with the children's educators, the authors investigate the use of computers and tablets for education purposes and accessing information, as well as for communication purposes with their families in their countries of origin.

Stefan Mertens, Olivier Standaert, Leen d'Haenens, and Rozane De Cock (2019) investigate the link between journalism cultures, migration and integration policies, and public opinion. In "Tolerance and Cultural Diversity in Western Countries" the authors analyze 24 countries for which data are available in the Migrant Integration Policy Index (MIPEX), the World Values Survey (WVS), and the Worlds of Journalism Study (WJS), in an effort to compare the journalists' role to promote tolerance and cultural diversity in society across countries with diverging migration and integration policies.
Eviane Cheng Leidig (2019) also deals with questions concerning immigration when exploring the role of Indian diasporic voices as mediators in populist radical right-wing discourse in the West in "Immigrant, Nationalist and Proud: A Twitter Analysis of Indian Diaspora Supporters for Brexit and Trump". This article presents a year-long data collection of a number of Indian diasporic individuals who took to Twitter to express proBrexit and pro-Trump views, in order to obtain insight into how social media may help construct ethnic and (trans)national identities, demarcating boundaries of inclusion and exclusion.

This thematic issue continues with two intersectional studies. Jeffrey Patterson and Koen Leurs (2019) in "We Live Here, and We Are Queer!: Young Adult Gay Connected Migrants' Transnational Ties and Integration in the Netherlands" provide valuable new insights into how sexual identification combined with bonding and bridging social capital diverge and converge among gay young adult forced migrants and voluntary ones, while considering the interplay between online and offline explorations and entanglements of their worlds.

The second intersectional contribution is "The Cancer's Margins Project: Access to Knowledge and Its Mobilization by LGBQ/T Cancer Patients" by Evan T. Taylor, Mary K. Bryson, Lorna Boschman, Tae Hart, Jacqueline Gahagan, Genevieve Rail and Janice Ristock (2019). The authors aim to document and analyze complex intersectional relationships between marginalization, gender and sexuality, when it comes to cancer health decisionmaking and care experiences, with a specific focus on knowledge access, sharing, and mobilization.

\section{Conclusion}

To sum up, the ten articles in this thematic issue of Media and Communication present empirical, analytical and theoretical investigations, reflecting research on communicating on and with minorities. All of these provide ample opportunities to further reflect on minorizing practices related to gender issues and sexual orientations, ethnic cultural background and migratory experience. We hope these contributions' fresh insights will further inspire our readers into innovative research on ways to communicate on and with minority communities around the world.

\section{Acknowledgements}

We would like to thank all the authors, as well as the numerous reviewers, and Rodrigo Gomes and Cátia Simões from the journal's editorial office for their valuable contributions to this issue.

\section{Conflict of Interests}

The authors declare no conflict of interest. 


\section{References}

Casado, M. A., Garitaonandia, C., Moreno, G., \& Jimenez, E. (2019). Immigrant children and the internet in Spain: Uses, opportunities and risks. Media and Communication, 7(1), 56-65.

De Coninck, D., Matthijs, K., Debrael, M., De Cock, R., \& d'Haenens, L. (2019). Unpacking attitudes on immigrants and refugees: A four-country comparison focusing on household composition and news media consumption. Media and Communication, 7(1), 43-55.

Garmendia, M., \& Karrera, I. (2019). ICT use and digital inclusion among Roma/Gitano adolescents. Media and Communication, 7(1), 22-31.

Leidig, E. C. (2019). Immigrant, nationalist and proud: A Twitter analysis of Indian diaspora supporters for Brexit and Trump. Media and Communication, 7(1), 77-89.

Mertens, S., Standaert, O., d'Haenens, L., \& De Cock, R. (2019). Tolerance and cultural diversity in western countries. The link between journalism culture, mi- gration integration policy and public opinion. Media and Communication, 7(1), 66-76.

Panis, K., Paulussen, S., \& Dhoest, A. (2019). Managing super-diversity on television: The representation of ethnic minorities in Flemish non-fiction programmes. Media and Communication, 7(1), 13-21.

Patterson, J., \& Leurs, K. (2019). We live here, and we are queer!: Young adult gay connected migrants' transnational ties and integration in the Netherlands. Media and Communication, 7(1), 90-101.

Ryan, D. P., \& Jamieson, P. E. (2019). Risk and culture of health portrayal in a U.S. cross-cultural TV adaptation, a pilot study. Media and Communication, 7(1), 32-42.

Taylor, E. T., Bryson, M. K., Boschman, L., Hart, T., Gahagan, J., Rail, G., \& Ristock, J. (2019). The cancer's margins project: Access to knowledge and its mobilization by LGBQ/T cancer patients. Media and Communication, 7(1), 102-113.

Vandenberghe, H. (2019). Representation of women in the news: Balancing between career and family life. Media and Communication, 7(1), 4-12.

\section{About the Authors}
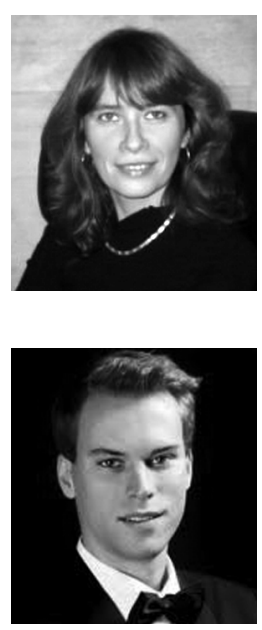

Leen d'Haenens is Full Professor in Communication Science at the Institute for Media Studies at KU Leuven, where she teaches media policy and analysis of media texts at BA level, and media consumption at MA level. Her research interests include digital media and youth, news media diversity, media and ethnic minorities, and media policy and governance mechanisms. She is a member of the Euromedia Research Group and Editor of Communications: The European Journal of Communication Research.

Willem Joris is a Postdoctoral Researcher at the Institute for Media Studies at KU Leuven, and Guest Professor in Communication Sciences at the Free University of Brussels (VUB). He is project manager of the BRAIN-be project IM²MEDIATE: The Image of Immigrants in the Media: Thought-provoking Effects. His research interests include news framing analysis, journalism studies, media policy, political communication, media and diversity, and Europe. 